\title{
Baboon graft fails, but patient thrives
}

Last December, researchers from the University of Pittsburgh and the University of California at San Francisco transplanted baboon bone marrow into an HIV-positive San Francisco man. The bid to buttress the man's deteriorating immune function with baboon immune cells, which are naturally resistant to HIV, has apparently not harmed the patient, AIDS activist Jeff Getty. Nor have the baboon cells engrafted, according to Suzanne Ildstad of Pittsburgh. Nevertheless, by several measures, Getty is healthier than he was before the procedure, which involved partial immune suppression to encourage baboon hematopoietic stem cells to take up residence in his marrow. He has left the hospital, gained weight, and the concentration of $\mathrm{CD}^{+} \mathrm{T}$ cells in his blood has increased. However, tests conducted on bone marrow sampled one month after the transplant do not consistently show the presence of baboon cells.

Stephen Deeks, of UCSF, concludes that the lack of conclusive evidence for baboon cell engraftment does not mean that the experiment was a failure. First, the question of engraftment is still open, says Deeks. Although he would expect to easily find baboon DNA in the one-month biopsy if engraftment were going to occur, it is possible that a few baboon stem cells persist in Getty's marrow and that their progeny will only be found later. But a more important point is that this study was designed as an initial test of the safety, not the efficacy, of the baboon bone marrow strategy. "The immune conditioning regimen we used was relatively mild, so that if we erred, we erred on the side of safety at the risk of lack of engraftment," Deeks and Ildstad report.

The researchers' concerns for safety were heightened by months of public controversy and bureaucratic wrangling that preceded the experiment. They received final approval only after a two-day hearing before a Food and Drug Administration advisory panel last July, at which safety issues and the usefulness of baboons as donors were debated. Baboons are endangered in the wild and expensive to breed, so that even if the procedure worked there would never be enough baboons to satisfy the potential demand.

The attention led the researchers to reduce the amount of immune suppression
Getty received and to strengthen their screening for baboon viruses that conceivably could be transmitted to humans. They apparently succeeded in their determination to do no harm, and they found neither evidence that baboon immune cells attacked their human host nor any indication that Getty was infected by any viruses of baboon origin. However, tests for any endogenous baboon retroviruses that may have been transmitted are still in progress at the Centers for Disease Control and Prevention in Atlanta.

Xenotransplantation of baboon bone marrow is the most highly publicized strategy to reconstitute immune function in people with HIV infection, but other strategies abound. These include transplantation of human bone marrow, treatment with regulatory cytokines such as interleukin-2,

These cells from the thymus have been successfully transplanted in a patient with DiGeorge syndrome.

ex vivo culture and reinfusion of a patient's T-cells - both with and without genetic engineering to boost their HIV resistance - and transplantation of thymus tissue from human donors.

According to Dani Bolognesi of Duke University, the recent demonstration that three-drug antiretroviral therapy - a cocktail of an HIV protease inhibitor and two nucleoside analogues, AZT and 3TC - can reduce the amount of active virus essentially to zero has brought the problem of immune system restoration back to center stage. "Now we need to focus on whether the immune system can heal by itself, or whether in some cases the virus has done so much damage that we have to intervene," he says. It might be that if the drugs are used early enough then the immune system can recover on it own. "But later in the course of infection, gaps may develop in the repertoire of immune cells that recognize different antigens."

One way to restore a broad diversity of $T$ cells is to give patients a functioning thymus, the organ in which $T$ cells mature throughout childhood and adolescence. The thymus is often seriously damaged by HIV. Transplant researchers Richard Hong of the University of Vermont and Louise Markert at Duke, now working with Bolognesi, have successfully transplanted neonatal thymus tissue into the leg muscles of a few children born with complete DiGeorge syndrome, in which the thymus is absent.

\section{Thymus transplantation}

Thymus transplantation, it is hoped, will replenish lost $\mathrm{T}$-cell populations. "In HIV, so many T cells are killed that many patients don't respond to some specific antigens," says Markert. Successful three-day drug therapy can allow T-cell counts to partially recover, "but as a clinical immunologist, I care about how well the cells respond to pathogens, not just how many there are." Ideally, a new thymus in AIDS patients will allow proper maturation of T-cell clones to replace those the virus has driven to extinction. Trials of the procedure in human volunteers should begin at Duke this spring.

\section{IMAGE UNAVAILABLE FOR COPYRIGHT REASONS}

As for the baboon graft experiment in San Francisco, Deeks says that he and his colleagues will continue to study Getty for several more months; additional trials are likely later this year, Ildstad says. The next round of experiments will use peripheral baboon blood, to which stem cells have been mobilized by treatment with cytokines. This strategy will allow several patients to be treated using just one baboon, which would not have to be killed.

Looking back on the controversy surrounding the San Francisco experiment, Deeks argues that there was more common ground than disagreement among its critics and advocates. "Reasonable people differ with the approach we took - both on how fast we moved and on the question of viral transmission-but most people do not want to stop this line of research."

ROBERT TAYLOR Washington, $D C$ 